
duas estações. Horticultura Brasileira 24: 141-145.

\title{
Qualidade do tomate em função de doses de nitrogênio e da adubação orgânica em duas estações ${ }^{1}$
}

\author{
Magna Maria M Ferreira ${ }^{2}$; Gilvan B Ferreira ${ }^{3}$; Paulo Cezar R Fontes ${ }^{4}$; José P Dantas ${ }^{5}$ \\ ${ }^{2}$ UFRR, EAgro, 69310-270 Boa vista-rr; ${ }^{3}$ Embrapa Roraima, C. Postal 123, 69310-970 Boa Vista-RR; ${ }^{4}$ UFV, Dept ${ }^{\circ}$ Fitotecnia, $36571-000$ \\ Viçosa-MG; ${ }^{5} \mathrm{UEPB}$, 58100-007 Campina Grande-PB; E-mail: magna.m.m.ferreira@ bol.com.br; \\ gilvanbf@dnpa.embrapa.br;pacerefo@mail.ufv.br; gpcnpq@terra.com.br
}

\section{RESUMO}

A qualidade dos frutos do tomateiro, medida pelo $\mathrm{pH}$, pelos sólidos solúveis totais, pela acidez total titulável e pelos teores de $\mathrm{N}$ $\mathrm{NO}_{3}{ }^{-}$na matéria seca, em resposta a doses de nitrogênio e a adubação orgânica, foi avaliada em dois experimentos de campo, conduzidos nas épocas: primavera/verão (nov/98 a fev/99) e outono/primavera (mai a out/99). Os experimentos foram instalados na horta da UFV. As doses de N aplicadas foram 0,0 e 0,0; 93,5 e 110,0; 187,0 e 220,0; 374,0 e 440,0; e 748,0 e 880,0 kg/ha, nos experimentos de primavera/verão e outono/primavera, respectivamente, e as doses de matéria orgânica na forma de esterco bovino curtido, em base seca, foram 0 e $8 \mathrm{t} / \mathrm{ha}$, nos dois experimentos. O delineamento experimental foi em blocos ao acaso no arranjo fatorial $5 \times 2$, com quatro repetições. Nas duas épocas, o pH, os sólidos solúveis totais e a acidez total titulável no fruto de tomate não se alteraram com o aumento nas doses de $\mathrm{N}$, tanto na ausência como na presença da adubação orgânica; os teores de $\mathrm{N}_{-} \mathrm{NO}_{3}^{-}$na matéria seca dos frutos aumentaram linearmente com as doses de $\mathrm{N}$, sem adubação orgânica; na presença, esta variável não se alterou com as doses de $\mathrm{N}$.

Palavras-chave: Lycopersicon esculentum, esterco bovino, $\mathrm{pH}$, ${ }^{0}$ Brix, acidez, nitrato.

\begin{abstract}
Tomato quality as a result of nitrogen doses and organic manuring in two stations

The tomato fruits quality, measured by $\mathrm{pH}$, by total soluble solids, by the entitled total acidity and by the $\mathrm{N}_{-} \mathrm{NO}_{3}{ }_{3}^{-}$and total $\mathrm{N}$ content in the dry matter, as a result of nitrogen doses and organic fertilization, was evaluated in two field experiments, conducted in spring/summer (nov/98 to feb/99) and autumn/spring (may/99 to oct/99). The experiments were carried out in Viçosa, Minas Gerais State, Brazil. The $\mathrm{N}$ doses were 0,0 and 0,$0 ; 93,5$ and 110,$0 ; 187,0$ and 220,0; 374,0 and 440,0; and 748,0 and $880,0 \mathrm{~kg} / \mathrm{ha}$, in spring/summer and autumn/spring experiments, respectively, and the doses of organic matter in the form of hardened cattle manure, in dry base, 0 and $8 \mathrm{t} /$ ha, in the experiments. The experimental design was of randomized blocks arranged in a $5 \times 2$ factorial design, with four replications. In the two periods, the $\mathrm{pH}$, the total soluble solids and the entitled total acidity in tomato fruits did not alter with the increase of $\mathrm{N}$ doses, without and with cattle manuring; the $\mathrm{N}^{-\mathrm{NO}_{3}}$ - content in the dry matter of the fruits increased linearly with the doses of $\mathrm{N}$, without cattle manuring; in the presence of cattle manure this variable was not influenced by $\mathrm{N}$ doses.
\end{abstract}

Keywords: Lycopersicon esculentum, bovine manure, $\mathrm{pH},{ }^{0}$ Brix, acidity, nitrate.

\section{(Recebido para publicação em 28 de maio de 2005; aceito em 10 de maio de 2006)}

$\mathrm{O}$ tomate é uma das hortaliças mais consumidas no Brasil e constitui importante fonte de vitaminas e sais minerais para o ser humano. Durante muitos anos, a produção quantitativa do tomateiro foi o principal critério na avaliação do efeito das práticas culturais sobre esta cultura, sendo a qualidade dos frutos pouco considerada. Entretanto, com os avanços das pesquisas, aumentando o potencial de produção do tomateiro e avaliando também os fatores relacionados à qualidade, mais ênfase tem sido dada ao efeito das práticas culturais sobre os aspectos qualitativos do tomate.

A maior parte dos fatores que determinam a qualidade dos produtos vege- tais é controlada geneticamente. Desta forma, a qualidade dos frutos do tomateiro difere entre as cultivares (Singh et al., 2000; Ravinder-Singh et al., 2001; Youssef et al., 2001; Warner et al., 2004), sendo também influenciada por outros fatores, como a fertilidade do solo e as condições climáticas.

Os nutrientes minerais podem influenciar os níveis de alguns compostos orgânicos nas plantas devido à influência que exercem sobre os processos bioquímicos ou físiológicos, como a atividade fotossintética e a taxa de translocação de fotoassimilados. Vários autores pesquisaram o efeito da disponibilidade de nitrogênio para as plantas de tomateiro sobre a qualidade dos seus frutos. Segundo Anaç et al. (1994), as principais características que devem ser consideradas na determinação da qualidade são: pH, concentração de sólidos solúveis, acidez total titulável, teores de vitamina $\mathrm{C}$ e de nitrato, coloração e peso fresco. Essas características podem ser afetadas pela fertilização nitrogenada (Armenta-Bojorquez et al., 2001; Oberly et al., 2002; Flores et al., 2003; Valencia et al., 2003; Warner et al., 2004). Para alcançar nutrição nitrogenada ótima e, consequentemente, altas taxa de crescimento, produção e qualidade dos frutos do tomateiro, sob condições de campo, a taxa de aplicação de fertilizante nitrogenado deve ser igual à alta demanda que ocorre duran-

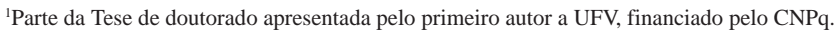


Tabela 1. Características químicas das amostras dos solos utilizados nos dois experimentos. Viçosa, UFV, 1998/1999.

\begin{tabular}{|c|c|c|c|c|c|c|c|c|c|c|}
\hline \multirow{4}{*}{ Experimento } & \multicolumn{10}{|c|}{ Características químicas } \\
\hline & \multirow{2}{*}{\multicolumn{3}{|c|}{$\mathrm{N}$ mineral ${ }^{1 /}(\mathrm{kg} / \mathrm{ha})$}} & \multirow{3}{*}{$\begin{array}{c}P \\
\left(\mathrm{mg} / \mathrm{dm}^{3}\right) \\
\end{array}$} & $\mathrm{K}+$ & $\mathrm{Ca}^{2+}$ & $\mathrm{Mg}^{2+}$ & $\mathrm{Al}^{3+}$ & $\mathrm{H}+\mathrm{Al}$ & $\mathrm{pH}$ \\
\hline & & & & & \multicolumn{6}{|c|}{$\left(\mathrm{cmol}_{c} / \mathrm{dm}^{3}\right)$} \\
\hline & $\begin{array}{c}0-20 \\
\mathrm{~cm}\end{array}$ & $\begin{array}{c}20-40 \\
\mathrm{~cm}\end{array}$ & $\begin{array}{c}40-60 \\
\mathrm{~cm}\end{array}$ & & \multicolumn{5}{|c|}{$0-20 \mathrm{~cm}$} & \\
\hline Primavera/verão & 39,81 & - & - & 21 & 51 & 0,9 & 0,0 & 0,3 & 3,3 & 4,3 \\
\hline Outono/primavera & 24,62 & 15,04 & 13,12 & 86 & 85 & 0,9 & 0,0 & 0,3 & 3,3 & 5,8 \\
\hline
\end{tabular}

${ }^{1}$ Obtido a partir do somatório dos teores de $\mathrm{N}^{-\mathrm{NO}_{3}}{ }^{-}$e $\mathrm{N}_{-} \mathrm{NH}_{4}^{+}$, e da multiplicação dos valores obtidos pelo volume de solo presente em cada um dos horizontes amostrados. P e K: extrator Melich-1; $\mathrm{N}_{-} \mathrm{NO}_{3}^{-}, \mathrm{N}-\mathrm{NH}_{4}^{+}, \mathrm{Al}^{3+}, \mathrm{Ca}^{2+} \mathrm{e} \mathrm{Mg}^{2+}$ : extrator $\mathrm{KCl} 1 \mathrm{~mol} / \mathrm{L} ; \mathrm{H}+\mathrm{Al}$ : extrator $\mathrm{Ca}$ $(\mathrm{Oac})_{2} 0,5 \mathrm{~mol} / \mathrm{L}$ a pH 7,0; $\mathrm{pH}$ em água, relação $1: 2,5$.

Tabela 2. Teores de umidade, matéria orgânica (M.O.) e nutrientes na matéria seca dos estercos bovinos utilizados nos dois experimentos. Viçosa, UFV, 1998/1999.

\begin{tabular}{|c|c|c|c|c|c|c|c|}
\hline \multirow{2}{*}{ Experimento } & Umidade & M.O. & $\mathbf{N}^{1 /}$ & $\mathbf{P}^{21}$ & $\mathbf{K}^{2 \prime}$ & $\mathrm{Ca}^{21}$ & $\mathbf{M g}^{2 \prime}$ \\
\hline & \multicolumn{2}{|c|}{$(\%)$} & \multicolumn{5}{|c|}{ (dag/kg) } \\
\hline Primavera/verão & 44 & 22,16 & 1,63 & 1,20 & 2,81 & 3,18 & 1,83 \\
\hline Outono/primavera & 17 & 49,45 & 2,06 & 0,84 & 2,35 & 0,83 & 0,57 \\
\hline
\end{tabular}

${ }^{1}$ Extraído com $\mathrm{H}_{2} \mathrm{SO}_{4}$ concentrado; ${ }^{2 /}$ Extração nítrico-perclórica 3:1

te os estádios de crescimento dos frutos, uma vez que a acumulação de sólidos solúveis ocorre durante este período e não no estádio de amadurecimento dos frutos (Yrisarry et al., 1993).

As condições climáticas como temperatura, umidade relativa e intensidade luminosa também exercem forte influência sobre as características qualitativas dos frutos de uma forma geral. Sendo assim, a época de cultivo pode influenciar significativamente a qualidade dos frutos de tomate. Supatra et al. (1998) verificaram que o tomate produzido no inverno, na Índia, apresentou melhor qualidade do que no verão em relação aos teores de sólidos solúveis, amido, nitrogênio, proteínas e aminoácidos. Por outro lado, Rodriguez et al. (1994), estudando o efeito do nitrogênio sobre as variáveis relacionadas à qualidade dos frutos do tomateiro em ampla faixa de variações climáticas e edáficas da Europa, constataram pouca variação nos resultados obtidos, indicando que estas variáveis são menos influenciadas pelo meio do que àquelas relacionadas à produção.

O objetivo deste trabalho foi avaliar os efeitos de doses de nitrogênio e da adubação orgânica sobre a qualidade de frutos do tomateiro, em duas épocas de plantio.

\section{MATERIAL E MÉTODOS}

Foram conduzidos dois experimentos: um na primavera/verão e o outro no outono/primavera, em duas áreas contíguas, localizadas na Horta do Fundão, pertencente à Universidade Federal de Viçosa. Foram avaliados os efeitos de doses de nitrogênio e da adubação orgânica sobre a qualidade de frutos do tomateiro (Lycopersicon esculentum Mill.) cv. Santa Clara, de hábito de crescimento indeterminado.

$\mathrm{O}$ experimento de primavera/verão foi conduzido no campo, de 13/11/98 a $11 / 02 / 99$. O de outono/primavera foi conduzido entre $14 / 05$ e $27 / 10 / 99$. Os dois experimentos foram conduzidos em solo da classe Argissolo Vermelho-Amarelo (Tabela 1), em duas áreas distintas. As amostras de solo foram retiradas antes da aplicação dos tratamentos.

Nos dois experimentos, os tratamentos foram constituídos de cinco doses de nitrogênio, em presença ou não de adubação orgânica. Foram testadas as doses de $\mathrm{N}$ correspondentes a 0,$0 ; 93,5$; 187,$0 ; 374,0$ e $748,0 \mathrm{~kg} / \mathrm{ha}$ no experimento de primavera/verão e 0,$0 ; 110,0$; 220,$0 ; 440,0$ e 880,0 no experimento de outono/primavera. Os níveis de matéria orgânica foram 0 e 8 t/ha de matéria seca de esterco bovino curtido, cuja caracterização química se encontra na Tabela 2. Os tratamentos foram distribuídos no delineamento em blocos ao acaso com quatro repetições, perfazendo o total de 40 unidades experimentais ou parcelas, no espaçamento de $1,0 \mathrm{~m}$ entre fileiras e 0,5 m entre plantas, no total de 28 plantas por parcela (4 fileiras com 7 plantas cada), sendo consideradas úteis as 10 plantas centrais da parcela. As dimensões de cada parcela foram $4 \mathrm{~m}$ de largura e 3,5 m de comprimento, ocupando área total de $14 \mathrm{~m}^{2}$, sendo $5 \mathrm{~m}^{2} \mathrm{de}$ área útil.

Para a análise da qualidade, foram amostrados cerca de seis frutos extra AA por parcela, escolhidos ao acaso entre aqueles da $4^{\mathrm{a}} \mathrm{e} 5^{\mathrm{a}}$ colheitas. Esses frutos foram acondicionados em sacos plásticos, devidamente identificados. No laboratório, todos os frutos foram lavados com água deionizada, secados em papel absorvente e, em seguida, três dos seis frutos passados em multiprocessador para a determinação do $\mathrm{pH}$, dos sólidos solúveis totais (Brix) e da acidez total titulável.

Os três frutos restantes foram secos em estufa de circulação forçada de ar, a $70^{\circ} \mathrm{C}$, até atingirem peso constante, e moídos em moinho tipo Wiley com peneira de 20 mesh. Na matéria seca dos frutos, após a extração com água em banho-maria, a $45^{\circ} \mathrm{C}$, durante 1 hora, foi determinada a concentração de $\mathrm{N}-\mathrm{NO}_{3}$, por colorimetria, em espectrofotômetro a $410 \mathrm{~nm}$.

Os dados obtidos foram submetidos à análise de variância e modelos de regressão foram ajustados relacionando-se as variáveis dependentes obtidas às doses de $\mathrm{N}$ aplicadas, nos dois níveis de matéria orgânica testados. Os modelos de regressão foram escolhidos com base no significado biológico do modelo, na significância dos coeficientes de regressão até $10 \%$ de probabilidade, pelo teste $t$, e no maior coeficiente de determinação.

\section{RESULTADOS E DISCUSSÃO}

\section{Experimento de Primavera/Verão}

$\mathrm{O} \mathrm{pH}$ dos frutos do tomateiro não foi alterado pelo aumento das doses de $\mathrm{N}$, atingindo os valores médios de 4,58 e 4,61, sem e com matéria orgânica adi- 
cionada ao solo, respectivamente. Estes resultados discordam daquele obtido por May \& Gonzales (1994), os quais constataram que doses altas de nitrogênio proporcionaram valores de $\mathrm{pH}$ dos frutos de tomate mais baixos do que as doses baixas. $\mathrm{O} \mathrm{pH}$ do fruto de tomate destinado ao processamento industrial deve estar entre 4,0 e 4,5, para inibir o crescimento de bactérias (Jones Júnior, 1999). No caso de tomate para mesa, ainda não existe padrão para essa variável.

Os sólidos solúveis totais dos frutos do tomateiro não foram alterados com o aumento das doses de N, nos dois níveis de matéria orgânica testados. Esses resultados estão de acordo com Pandey et al. (1998), Singh (2003) e Warner et al. (2004), os quais, estudando o efeito do nitrogênio no solo sobre a concentração de sólidos solúveis em frutos de tomate, constataram que essa variável não se alterou com o aumento das doses de N. Por outro lado Anaç et al. (1994) e Valencia et al. (2003) verificaram aumento constante da concentração de sólidos solúveis em frutos de tomate com o aumento na quantidade de fertilizante nitrogenado enquanto Ravinder-Singh et al. (2001) e Duraisami \& Mani (2002) verificaram efeito inverso, ou seja, diminuição do valor dessa variável com o aumento da taxa de $\mathrm{N}$ no solo.

A percentagem de sólidos solúveis totais está relacionada, principalmente, ao sabor do fruto e é representada pelo Brix. A maior parte das cultivares de tomateiro produz frutos que contêm Brix variando de 5,0 a 7,0. No presente trabalho, os valores médios foram 3,75 e 3,57 , sem e com matéria orgânica adicionada ao solo, respectivamente, indicando que as condições ambientais e culturais dadas às plantas de tomate não proporcionaram alto teor de sólidos solúveis. Deste teor, cerca da metade é composta de açúcares e 1/8 de ácidos, sendo que os açucares predominantes são glicose e frutose e o ácido predominante é o cítrico (Jones Júnior, 1999).

A percentagem de sólidos solúveis totais influencia significativamente o rendimento industrial, principalmente o peso final do produto processado. Em alguns países desenvolvidos, a percentagem de sólidos solúveis é utilizada

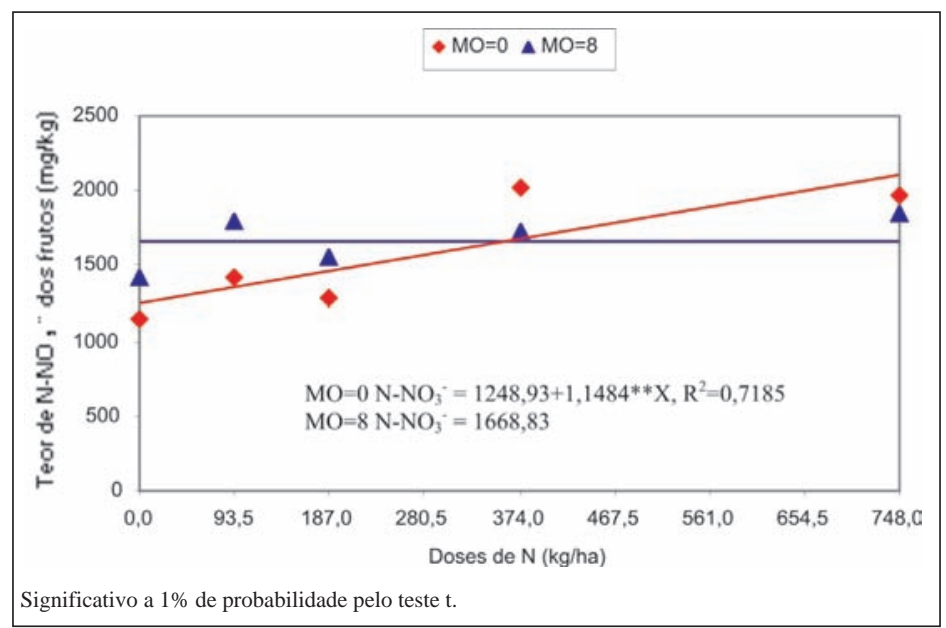

Figura 1. Teores de $\mathrm{N}^{-\mathrm{NO}_{3}}{ }^{-}$na matéria seca dos frutos do tomateiro em função das doses de nitrogênio $(\mathrm{N})$ e da matéria orgânica ( $\mathrm{MO}$, em t/ha), do experimento de primavera/verão. Viçosa, UFV, 1999.

como base na determinação do preço do tomate destinado ao processamento industrial. Desta forma, é importante que seja definido o papel de certos fatores edáficos na determinação dessa característica (Mahmoud \& Amara, 2000; Colla et al., 2001; Kumaran \& Natarajan, 2001). O nitrogênio desempenha importante papel na biossíntese de açúcares nas folhas, os quais podem ser translocados para os frutos, podendo, ao contrário do que ocorreu no presente experimento, aumentar a concentração de sólidos solúveis destes. Como houve resposta acentuada da produção total de frutos ao incremento das doses de N, nos dois níveis de adubação orgânica testados, alcançando os valores de 22,$13 ; 37,14 ; 42,46 ; 42,61$ e 44,44 t/ha, sem matéria orgânica, e 29,41; 37,38; 37,89; 43,61 e 44,45 t/ha, com matéria orgânica adicionada ao solo, nas doses de 0,$0 ; 93,5 ; 187,0 ; 374,0$ e $748,0 \mathrm{~kg} / \mathrm{ha}$ de $\mathrm{N}$, respectivamente, é possível que os açúcares produzidos nas folhas durante o processo de fotossíntese tenham sido destinados para o aumento no peso e no número de frutos por planta nesta cultivar (Santa Clara), segundo constatações de Ferreira et al. (2003).

Dadomo et al. (1994) evidenciaram que não apenas os teores de sólidos solúveis nos frutos de tomate devem ser levados em consideração, como também a quantidade produzida por unidade de área. Desta forma, no presente experimento, foram produzidos, em média, 945 e 924 kg/ha de sólidos solúveis, sem e com adição de matéria orgânica ao solo, respectivamente.

A acidez total titulável dos frutos do tomateiro, representada pela percentagem de ácido cítrico, não foi alterada com o aumento das doses de N, nos dois níveis de matéria orgânica testados, atingindo os valores médios de $0,382 \%$ e $0,375 \%$, sem e com adubação orgânica, respectivamente, concordando com os resultados obtidos por Durasaimi \& Mani (2002) e Oberly et al. (2002), e discordando com a afirmativa feita por Kaniszewski \& Rumpel (1983) de que a fertilização nitrogenada pode afetar a acidez total titulável dos frutos de tomate, conforme demonstrado por Ravinder et al. (2000) e Singh et al. (2000). Além da nutrição nitrogenada, outros fatores como genótipo, irradiação e temperatura podem influenciar a coloração, o teor de açucares e a acidez total titulável do tomate. O sabor dos frutos de tomate é importante característica qualitativa que atrai bastante a atenção do consumidor. De acordo com Peet (1996d), citado por Jones Júnior (1999), quanto maiores a acidez e o teor de açúcares, melhor será o sabor do tomate.

$\mathrm{O}$ teor de $\mathrm{N}_{-} \mathrm{NO}_{3}^{-}$na matéria seca dos frutos do tomateiro aumentou linear- 


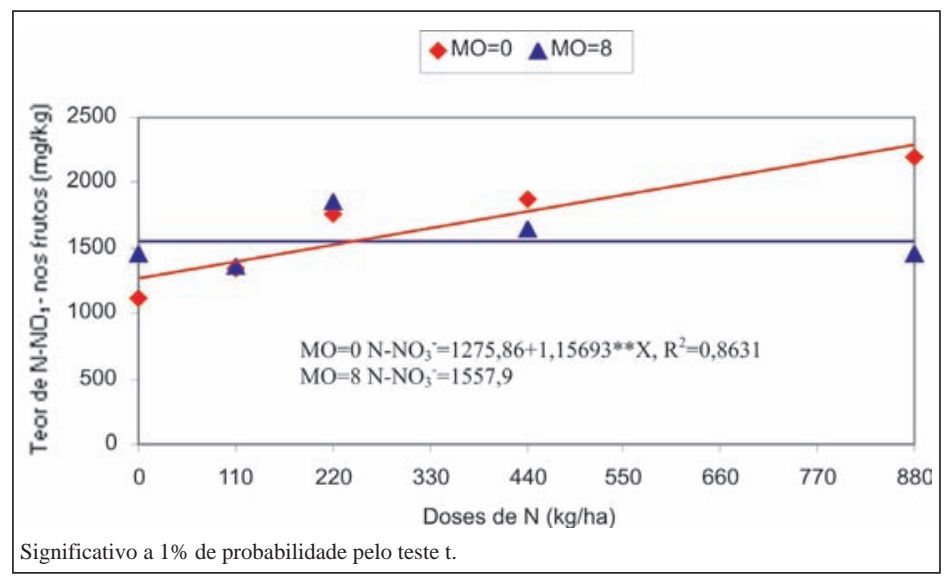

Figura 2. Teores de $\mathrm{N}_{-} \mathrm{NO}_{3}^{-}$na matéria seca dos frutos do tomateiro em função das doses de nitrogênio $(\mathrm{N})$ e da matéria orgânica ( $\mathrm{MO}$, em t/ha), do experimento de outono/primavera. Viçosa, UFV, 1999.

mente com as doses de $\mathrm{N}$ sem adição de matéria orgânica ao solo e permaneceu constante com adição (Figura 1). O resultado obtido sem adição de matéria orgânica ao solo está de acordo com a afirmativa de Kaniszewski \& Rumpel (1983) de que a fertilização nitrogenada pode afetar tanto positiva como negativamente algumas características da qualidade dos frutos de tomate, tais como teores de matéria seca e de nitrato na matéria seca. Kaniszewski et al. (1987) verificaram que o incremento do nível de $\mathrm{N}$ no solo aumentou o teor de nitrato na matéria seca dos frutos. Resultados semelhantes foram obtidos por Mahmoud \& Amara (2000). Com a dose zero de $\mathrm{N}$ no solo, os teores de $\mathrm{N}_{-} \mathrm{NO}_{3}$ na matéria seca dos frutos de tomate foram 1153 e $1418 \mathrm{mg} / \mathrm{kg}$, sem e com adubação orgânica, respectivamente.

$\mathrm{O}$ teor de $\mathrm{N}_{-} \mathrm{NO}_{3}^{-}$na matéria seca dos frutos, sem adição de matéria orgânica ao solo, com a dose de nitrogênio que proporcionou a produção equivalente a frutos extra AA(PEAA) de máxima eficiência econômica (MEE), 355,2 kg/ha, foi $1657 \mathrm{mg} / \mathrm{kg}$. Tal valor encontra-se acima da faixa encontrada por Kaniszewski et al. (1987), que foi 57,3-145,1 mg/kg. Essa discrepância pode ser atribuída a diversos fatores, entre os quais cultivares, manejo da cultura, produtividade e quantidade de $\mathrm{N}$ adicionada ao solo.

\section{Experimento de Outono/Primavera}

$\mathrm{O}$ pH, os sólidos solúveis totais (Brix) e a acidez total titulável, repre- sentada pela percentagem de ácido cítrico, dos frutos do tomateiro, não foram alterados com o aumento das doses de $\mathrm{N}$ no solo, nos dois níveis de matéria orgânica testados. $\mathrm{O}$ pH atingiu os valores médios de 4,69 e 4,68; o ${ }^{\circ}$ Brix, 3,93 e 3,94 e a acidez total titulável, $0,389 \%$ e $0,398 \%$ de ácido cítrico, sem e com adubação orgânica, respectivamente. Wight et al. (1962) também não encontraram variação em algumas características da qualidade de frutos do tomateiro, entre elas $\mathrm{pH} \mathrm{e}{ }^{\circ} \mathrm{Brix}$, com o aumento da taxa de fertilizantes nitrogenados no solo. Os resultados obtidos também estão de acordo com Pandey et al. (1998), os quais constataram que a fertilização nitrogenada não afetou os sólidos solúveis totais, a acidez total titulável e o teor de ácido ascórbico nos frutos de tomate. De acordo com Warner et al. (2004), que trabalhou com cultivares de tomate para processamento em Ontário, Canadá, a taxa de $\mathrm{N}$ no solo não afeta os sólidos solúveis totais, a firmeza, o tamanho e a coloração dos frutos comercializáveis. Desta forma, Wight et al. (1962) sugerem que o programa de adubação com $\mathrm{N}$ nesta cultura deve ser feito com base nos benefícios trazidos à produção e não à qualidade dos frutos.

Semelhante ao que ocorreu no experimento de primavera/verão, o teor de $\mathrm{N}-\mathrm{NO}_{3}^{-}$na matéria seca dos frutos do tomateiro aumentou linearmente com as doses de $\mathrm{N}$ sem adição de matéria orgânica ao solo e permaneceu constante com adição (Figura 2). Com a dose zero de $\mathrm{N}$ no solo, tais teores foram, respectivamente, 1,66 e $1,77 \mathrm{dag} / \mathrm{kg}$, sem adição de matéria orgânica ao solo, e 1,94 e 2,09 dag/kg, com adição. Com a dose zero de $\mathrm{N}$ no solo, os teores de $\mathrm{N}-\mathrm{NO}_{3}$ na matéria seca dos frutos de tomate foram 1111 e $1467 \mathrm{mg} / \mathrm{kg}$, sem e com adubação orgânica, respectivamente. $\mathrm{O}$ teor de nitrato nos frutos, sem adubação orgânica, correspondente à dose de nitrogênio no solo que proporcionou a PEAA de MEE, ou seja, 525,8 kg/ha, foi $1884 \mathrm{mg} / \mathrm{kg}$. Segundo a Organização Mundial da Saúde, citada por Toyohara (1989), a ingestão diária aceitável para nitrato para o homem é de 5 $\mathrm{mg} / \mathrm{kg}$ de peso corporal. Portanto, um adulto com $70 \mathrm{~kg}$ não deve ingerir mais de $350 \mathrm{mg} /$ dia de nitrato. Como a cv. utilizada no presente experimento (Santa Clara) pode possuir um peso médio de $140 \mathrm{~g} /$ fruto, o consumo de 1 fruto/ dia por um adulto de $70 \mathrm{~kg}$ não acarretaria problemas de intoxicação, pois o mesmo estaria ingerido 263,76 mg de nitrato. O valor encontrado, semelhante ao que ocorreu no experimento de primavera/verão, se encontra muito acima da faixa encontrada por Kaniszewski et al. (1987).

Em ambas as épocas, o pH, os sólidos solúveis totais e a acidez total titulável no suco de tomate não se alteram com o aumento nas doses de N, sem ou com adubação orgânica; os teores de $\mathrm{N}_{-} \mathrm{NO}_{3}^{-}$na matéria seca aumentam linearmente na ausência da adubação orgânica e permanecem constantes na presença.

\section{AGRADECIMENTOS}

Os autores agradecem aos funcionários da Horta do Fundão da Universidade Federal de Viçosa que viabilizaram a execução dos experimentos de campo.

\section{REFERÊNCIAS}

ANAÇ D; ERIUCE N; KILINÇ R. 1994. Effect of N, P, K fertilizer levels on yield and quality properties of processing tomatoes in Turkey. Acta Horticulturae 376: 243-250.

ARMENTA-BOJORQUEZ AD; BACACASTILLO GA; ALCANTAR-GONZALES G; KOHASHI-SHIBATA J; VALENZUELAURETA JG; MARTINEZ-GARZA A. 2001. Nitrate and potassium ratios in a drip fertigation system on production, quality and nutrient uptake in tomato. Revista ChapingoSérie Horticultura 7: 61-75. 
COLLA G; MITCHELL JP; POUDEL DD SACCARDO F; HARTZ TK. 2001. Impact of farming systems and soil characteristics on processing tomato fruit quality. Acta Horticulturae 542: 333-341.

DADOMO M; GAINZA AM; DUMAS Y; BUSSIÈRES P; MACUA JI; CHRISTOU M BRANTHÔME X. 1994. Influence of water and nitrogen availability on yield components of processing tomato in the European Union countries. Acta Horticulturae 376: 271-274.

DURAISAMI VP; MANI AK. 2002. Effect of major nutrients on yield and fruit quality of tomato under rainfed condition in Entisol. South Indian Horticulture 50: 56-64.

FERREIRA MMM; FERREIRA GB; FONTES PCR; DANTAS JP. 2003. Produção do tomateiro em função de doses de nitrogênio e da adubação orgânica em duas épocas de cultivo. Horticultura Brasileira 21: 471-476.

FLORES P; NAVARRO JM; CARVAJAL M; CERDA A; MARTINEZ V. 2003. Tomato yield and quality as affected by nitrogen source and salinity. Agronomie 23: 249-256.

JONES JÚNIOR JB. 1999. Tomato plant culture: in the field, greenhouse and home garden. Florida: CRC Press. 199p.

KANISZEWSKI S; ELKNER K; RUMPEL J. 1987. Effect of nitrogen fertilization and irrigation on yield, nitrogen status in plants and quality of fruits of direct seeded tomatoes. Acta Horticulturae 200: 195-202.

KANISZEWSKI S; RUMPEL J. 1983. The effect of nitrogen fertilization on the yield, nutrient status and quality of tomatoes under single and multiple harvest. Biul. Warzyw., Suplement. p. 19-29.
KUMARAN SS; NATARAJAN S. 2001 Efficiency of soil conditioners and recommended fertilizers on quality parameters of rainfed tomato. South Indian Horticulture 49: 199-201.

MAHMOUD HAF; AMARA MAT. 2000. Response of tomato to biological and mineral fertilizers under calcareous soil conditions. Bulletin of Faculty of Agriculture-University of Cairo 51: 151-174.

MAY DM; GONZALES J.1994 . Irrigation and nitrogen management as they affect fruit quality and yield of processing tomatoes. Acta Horticulturae 376: 227-234.

OBERLY A; KUSHAD M; MASIUNAS J. 2002. Nitrogen and tillage effects on the fruit quality and yield of four tomato cultivars. Journal of Vegetable Crop Production 8: 65-79.

PANDEY RP; SARAF RK; PARIHAR MS. 1998. Effect of nitrogen, phosphorus and varieties on quality of tomato (Lycopersicon esculentum Mill.). Punjab Vegetable Grower 33:15-18.

RAVINDER-SINGH; KOHLI UK; KANWAR HS; SINGH R. 2001. Tomato fruit quality as influenced by different nutrient regimes. Himachal Journal of Agricultural Research 25: 37-42.

RODRIGUEZ A; LEONI S; BUSSIERES P; DADOMO M; CHRISTOU M; MACUA IJ; CORNILLON P. 1994. The influence of water and nitrogen levels on the quality of the processing tomato grown in European Union countries. Acta Horticulturae 376: 275-278.

SINGH AK; SHARMA JP; SINGH RK. 2000. Effect of variety and level of nitrogen on fruit quality of tomato hybrid (Lycopersicon esculentum Mill.). Journal of Research-Birsa Agricultural University 12: 205-208.
SINGH RV. 2003. Response of rainy-season tomato to $\mathrm{N}$ and $\mathrm{P}$ fertilizers, and plant spacing in the eastern plateau region. Indian Journal of Horticulture 60: 79-83.

SUPATRA S; MUKHERJI S; SEN S. 1998. Influence of seasons in determining the date of sowing and fruit quality of Abelmoschus esculentus (L.) Moench (okra) and Lycopersicon esculentum Mill. (tomato). Indian Agriculturist 42: 161-166.

TOYOHARA OQ. 1989. Determinação de nitrato, nitrite e $N$-nitrosaminas em linguiças. Campinas: UNICAMP. 85p (Tese mestrado).

VALENCIA J; BIECHE B; BRANTHOME X. 2003. Effect of fertilizers on fruit quality of processing tomatoes. Acta Horticulturae 613: 89-93.

WARNER J; ZHANG TQ; HAO X. 2004. Effects of nitrogen fertilization on fruit yield and quality of processing tomatoes. Canadian Journal of Plant Science 84: 865-871.

WIGHT JR; LINGLE JC; FLOCKER WJ; LEONARD SJ. 1962. The effects of irrigation and nitrogen fertilization treatments on the yield, maturation, and quality of canning tomatoes. Proceedings of the American Society for Horticultural Science 81: 451-457.

YOUSSEF AM; El-FOULY AHM; YOUSSEF MS; MOHAMEDIEN SA. 2001. Effect of using organic and chemical fertilizers in fertigation system on yield and fruit quality of tomato. Egyptian Journal of Horticuculture 28: 59-77.

YRISARRY JJB; LOSADA MHP; RINCÓN AR. 1993. Response of processing tomato to three different levels of water and nitrogen applications. Acta Horticulturae 355: 149-156. 